\title{
AS ROTINAS E ATIVIDADES PERMANENTES NA EDUCAÇÃO INFANTIL
}

\author{
Denis de Moares dias dos Santos ${ }^{1}$ \\ Jucilene Campos de Almeida ${ }^{2}$ \\ Marlene Santana de Sene ${ }^{3}$ \\ Maria Marlene Pinheiro Silva ${ }^{4}$
}

RESUMO: Podemos destacar, como um marco importante, a promulgação da última Lei de Diretrizes e Bases da Educação Brasileira - LDB 9394/96, em 1996, quando foi definido que as creches, em todos os municípios brasileiros, não poderiam ser mais interligadas às Secretarias de Ação Social, perdendo seu caráter assistencialista. Isto significa que o foco do cuidado, comumente efetivado nas creches brasileiras, até então, foi se interligando às preocupações educativas. Em atenção à rotina na Educação Infantil sempre foi permeada pelas mais diversas significações e concepções ao longo do tempo, sendo compreendida como amarra, disciplinadora de almas pequenas, além de estruturante e significante para educadores e educandos. Esta trajetória tem sido compreendida - e desenvolvida - de diversas perspectivas, sendo possível perceber, ao longo da existência das instituições de educação infantil, em sua organização - e sua função - influências de diversas ordens, como religiosa, filosófica, médica, psicológica e biológica, refletindo e, ao mesmo tempo, promovendo as reconstruções do conceito de rotina na educação infantil.

Palavras- chave: Educação Básica. Educação Infantil. Rotina.

\section{APRESENTAÇÃO}

A Educação Infantil tem passado por mudanças ao longo de sua trajetória e podemos destacar, como um marco importante, a promulgação da última Lei de Diretrizes e Bases da Educação Brasileira - LDB 9394/96, em 1996, quando foi definido que as creches, em todos os municípios brasileiros, não poderiam ser mais interligadas às Secretarias de Ação Social, perdendo seu caráter assistencialista. Passou a integrar a educação básica e, consequentemente, vem tornando-se paulatinamente responsabilidade das secretarias de educação dos municípios. Isto significa que o foco do cuidado, comumente efetivado nas

\footnotetext{
I Graduada em pedagogia pela Faculdade Anhanguera e pós-graduada em Ludo pedagogia pela Facitec. ${ }^{2}$ Graduada em licenciatura em Pedagogia com ênfase na Educação Infantil pela NEAD/UFMT.

${ }^{3}$ Graduada em Licenciatura em pedagogia pela universidade de Cuiabá e pós-graduada em Educação Infantil e Alfabetização pela Faculdade Invest de Ciências e Tecnologia. E-mail: marlenesenei4@hotmail.com ${ }^{4}$ Graduada em Pedagogia pela Unic Universidade de Cuiabá.
} 
creches brasileiras, até então, foi se interligando às preocupações educativas. $\mathrm{Na}$ verdade, segundo Sônia Kramer (2005), este processo vem sendo implementado desde 1988, a partir da aprovação da Constituição Federal de 1988 (art.208, inciso IV).

A rotina sempre esteve presente nas mais diversas organizações sociais. Seja em qualquer esfera política ou social há uma organização do tempo, o que também acontece na esfera educacional. Entretanto, para essa organização promover muito mais que uma orientação entre o espaço-tempo, ela deve estar intrinsecamente relacionada com o meio ao qual se aplica, sobretudo no contexto pedagógico. A rotina na educação infantil sempre foi permeada pelas mais diversas significações e concepções ao longo do tempo, sendo compreendida como amarra, disciplinadora de almas pequenas, além de estruturante e significante para educadores e educandos. Esta trajetória tem sido compreendida - e desenvolvida - de diversas perspectivas, sendo possível perceber, ao longo da existência das instituições de educação infantil, em sua organização - e sua função - influências de diversas ordens, como religiosa, filosófica, médica, psicológica e biológica, refletindo e, ao mesmo tempo, promovendo as reconstruções do conceito de rotina na educação infantil.

Considerando essa trajetória histórica e as diferentes ressignificações da rotina no contexto educacional, buscamos sistematizar, nesta pesquisa, um resgate histórico da compreensão relativa à Educação Infantil e à rotina como parte de sua estruturação, norteando-nos por uma questão central: quais as concepções docentes relativas às atividades permanentes nas rotinas de Educação Infantil?

Para conseguir entender um pouco destas duvidas, foi realizado uma análise em uma unidade de educação infantil que prioriza as rotinas e as atividades permanentes como organização pedagógica importante para o desenvolvimento cognitivo da criança.

\section{Referencial Curricular Nacional para a Educação Infantil}

O Referencial Curricular Nacional para a Educação Infantil (RCNEI) foi elaborado com o intuito de contribuir com a melhoria da prática pedagógica dos professores que atuam nesse nível de ensino, socializando e ampliando informações e pesquisas nessa área (BRASIL, 1998).O Referencial Curricular foi dividido em três volumes:I-) Introdução, 2-) 
Formação Pessoal e Social e 3-) Conhecimento de Mundo. Neles, estão contidas as diretrizes norteadoras da prática pedagógica do professor que atua em creches e pré-escolas brasileiras.

2.I Volume I

O volume I refere-se ao documento introdutório do Referencial, por isso ele apresenta as suas principais características e aborda diversos conceitos tais como: o conceito de criança, a importância entre o cuidar e o educar, o brincar nesse nível de ensino, e questões referentes a diversidade, individualidade, aprendizagem significativa, conhecimentos prévios e resolução de problemas. Além disso, também aponta que o professor deve desempenhar o papel de mediador do conhecimento e ao planejar as atividades diárias precisa levar em consideração a idade das crianças, os conteúdos propostos, os objetivos gerais da instituição, bem como, o tempo e o espaço disponíveis.

\subsection{Volume 2}

No volume 2, encontramos questões relacionadas a formação pessoal e social da criança, com o intuito de orientar os professores que atuam na Educação Infantil sobre a forma de trabalhar a identidade e autonomia da criança. Este volume mostra a importância de criar situações educativas e coletivas para que cada criança possa ter seus hábitos e preferências respeitadas. Também aponta como devemos proceder diante das falas das crianças para estabelecer a autoconfiança e a construção de sua identidade e autonomia. As crianças que freqüentam as instituições de Educação Infantil estão ligadas a um círculo de diversidade cultural em seu dia a dia que resultam em valores, crenças e conhecimentos. Por isso, o Referencial Curricular Nacional (BRASIL, 1998) afirma que conhecer as características e potencialidades das crianças, e ao mesmo tempo, reconhecer seus limites é essencial para o desenvolvimento da sua identidade e para a conquista da autonomia. (BRASIL, 1998).

\subsection{Volume 3}

O volume 3 é denominado "Conhecimento do Mundo" e foi organizado em 6 documentos: Movimento, Música, Artes Visuais, Linguagem Oral e Escrita, Natureza e Sociedade e Matemática. O movimento surge desde o nascimento e com o passar dos anos a criança vai adquirindo cada vez mais o controle de seu corpo, expressando seus sentimentos, emoções e pensamentos. Ao brincar, jogar, imitar e criar ritmos e movimentos 
a criança se apropria do repertório da cultura corporal na qual está inserido. Por isso, as instituições de ensino devem criar um ambiente físico e social propício para a realização de diversas atividades de movimento, para que a criança se sinta protegida e acolhida, ao mesmo tempo, confiante para se arriscar e vencer desafios. (BRASIL, I998). Em relação a música, podemos dizer que a mesma é traduzida em formas sonoras, capaz de expressar, comunicar sensações, sentimentos e pensamentos, a partir do som e do silêncio. A música está presente em todas as culturas e é uma importante forma de comunicação para o ser humano. (BRASIL, 1998).

O Referencial Curricular Nacional para a Educação Infantil ressalta em seus documentos que a criança é um sujeito de direitos e, portanto, deve ser respeitado e considerado todas as suas diferenças individuais, sociais, étnicas, econômica, culturais, religiosas, etc. Além disso, a criança tem o direito de viver experiências prazerosas, afetivas, emocionais, sociais e cognitivas nas instituições de Educação Infantil. (BRASIL, 1998). Em relação as práticas pedagógicas presentes nesse nível de ensino, o RCNEI mostra que essas devem se organizar de modo que as crianças desenvolvam as seguintes capacidades:

Desenvolver uma imagem positiva de si, atuando de forma cada vez independente, com confiança em suas capacidades e percepção de suas limitações.

Descobrir e conhecer progressivamente seu próprio corpo, suas potencialidades e seus limites, desenvolvendo e valorizando hábitos de cuidado com a própria saúde e bem-estar.

Estabelecer e ampliar cada vez mais as relações sociais, aprendendo aos poucos a articular seus interesses e pontos de vista com os demais, respeitando a diversidade e desenvolvendo atitudes de ajuda e colaboração.

Observar e explorar o ambiente com atitude de curiosidade, percebendo-se cada vez mais integrante, dependente e agente transformador do meio ambiente e valorizando atitudes que contribuem para sua conservação.

Brincar, expressando emoções, sentimentos, pensamentos, desejos e necessidades. 
Utilizar diferentes linguagens (corporal, musical, plástica, oral e escrita) ajustadas as diferentes intenções e situações de comunicação, de forma a compreender e ser compreendido, expressar suas idéias, sentimentos, necessidades e desejos e avançar no seu processo de construção de significados, enriquecendo cada vez mais sua capacidade expressiva.

Conhecer algumas manifestações culturais, demonstrando atitudes de interesse, respeito e participação frente a elas e valorizando a diversidade. (BRASIL, I998, p. $63)$.

Portanto, os professores de Educação Infantil devem utilizar o RCNEI para organizarem e complementarem a rotina escolar, buscando uma melhoria na sua prática pedagógica, bem como, no processo de ensino e aprendizagem.

\section{ORGANIZAÇÃO DO TEMPO PEDAGÓGICO: A rotina na Educação Infantil}

A organização do tempo pedagógico apresenta uma dinâmica multifacetada, por isso o professor deve perceber as diversas relações sociais entre as crianças e também os gostos e necessidades individuais e coletivas. A rotina deve ser planejada, porém flexível, devendo envolver o cuidado, o ensino e as especificidades imaginativas da criança, segundo o Referencial Curricular Nacional para Educação Infantil (RCNEI):

\section{A rotina representa, também, a estrutura sobre a qual será organizado o tempo didático, ou seja, o tempo de trabalho educativo realizado com as crianças. A rotina deve envolver os cuidados, as brincadeiras e a situações de aprendizagens orientadas. (BRASIL, V.I, 1998, p.54)}

Sendo assim, a organização do tempo no espaço educacional está inerentemente ligada às atividades que são propostas para o seu desenvolvimento, além do suprimento das necessidades básicas da criança.

O educador deve refletir sobre a construção desse planejamento, pois, de acordo com Proença (2004, p.13):

A rotina estruturante é como uma âncora do dia-a-dia, capaz de estruturar o cotidiano por representar para a criança e para os professores uma fonte de segurança e de previsão do que vai acontecer. Ela norteia, organiza e orienta o grupo no espaço escolar, diminuindo a ansiedade a respeito do que é imprevisível ou desconhecido e otimizando o tempo disponível do grupo. É um exercício disciplinar a construção da rotina do grupo, que envolve prioridades, opções, adequações às necessidades e dosagem das atividades. A associação da palavra 
âncora ao conceito de rotina pretende representar a base sobre a qual o professor se alicerça para poder prosseguir com o trabalho pedagógico.

E ainda observando o que dizem os documentos oficiais acerca da organização das rotinas escolares, entre eles o Referencial Curricular Nacional, o qual traz referências de como o tempo pedagógico pode ser organizado, encontramos a descrição do que seriam as atividades denominadas permanentes que estão dispostas ao longo deste capítulo. Segundo BRASIL (I998, p.55 e 56, vol I) as atividades permanentes podem ser:

Brincadeiras em espaços internos e externos;

Roda de história;

Roda de conversa;

Hora das refeições

Ateliês ou oficinas de desenho, pintura, modelagem e música;

Atividades diversificadas ou ambientes organizados por temas ou materiais escolha da criança, incluindo momentos para as crianças ficarem sozinhas se desejarem;

Cuidados com o corpo.

Essas atividades partem do pressuposto da organização do tempo educacional a partir de uma leitura que o educador faz de seus educandos, pois, Barbosa e Horn (200I) acreditam que essa leitura deve observar quais as preferências dos alunos e que comportamentos eles apresentam nas mais diversas situações. O educador deve perceber, ainda, em quais momentos as atividades permanentes são viáveis e necessárias, sempre considerando o contexto sociocultural da proposta pedagógica da instituição, pois as atividades permanentes promovem o desenvolvimento da autonomia e construção da identidade das crianças, e cada atividade propõe diversas situações seja de cuidado, higiene ou prazer

HORA DA RODA: é um dos momentos mais importantes, pois ao receber as crianças o professor proporciona segurança após a chegada, conversando com as crianças sobre as atividades que serão realizadas naquele dia, estimulando-as a contarem as suas vivências, trabalhando o calendário, a chamada e escolhendo o ajudante do dia.

No que se diz respeito a jogos e brincadeiras, é necessário que o educador tenha ciência da necessidade dessa atividade no cotidiano infantil, como é proposto no RCNEI: 
Para que o faz-de-conta torne-se de fato, uma prática cotidiana entre as crianças é preciso que se organize na sala um espaço para essa atividade, separado por uma cortina, biombo ou recurso qualquer, no qual as crianças poderão se esconder, fantasiar-se, brincar, sozinhas ou em grupos, de casinha, construir uma nave espacial ou um trem etc. (BRASIL, V.3, 1998, p.49)

Sendo assim, o educador deve procurar trazer à sala de aula a possibilidade do jogo e da brincadeira em um espaço reservado de preferência claro e com materiais dispostos para as crianças, ter um tempo disponível para essa atividade, tendo consciência de suas três funções no momento do faz-de-conta.

Nos ateliês ou oficinas de artes visuais ou musicais, é preciso que o educador possa não apenas estabelecer relações de cuidado com as crianças pequenas como também de aprendizagem. Gomes (200I) indica o trabalho artístico como importante para que as crianças possam explorar o mundo à sua volta. No entanto, por muito tempo a arte foi entendida superficialmente e de modo arbitrário.

As atividades diversificadas podem estar envolvidas em um projeto em que se possa trabalhar os mais diversos assuntos, o importante é que as atividades tenham um objetivo e não sejam descontextualizadas. Pelo contrário, devem integrar-se de forma a levar ao aluno a uma totalidade.

\footnotetext{
Vários projetos relacionados ao faz-de-conta podem ser desenvolvidos, tais como a construção de um cenário para uma viagem intergaláctica; a confecção de fantasias para brincar de bumba meu-boi; construir castelos de reis e rainhas; cenas de histórias e contos de fadas etc. Pode-se planejar um projeto de realização de um circo, por exemplo, com todas as crianças da Instituição, envolvendo cada grupo em função da idade e das capacidades. (BRASIL, 1998, p. 65, vol. I)
}

HORA DAS REFEIÇÕES: momento essencial para desenvolvimento saudável da criança, além de fazer parte do processo educativo. Durante as refeições, a criança tem a oportunidade de relacionar-se com o outro, adquirir muitos conhecimentos e ao mesmo tempo desenvolver sua autonomia. Comer nãoé apenas uma necessidade do organismo, mas também uma necessidade psicológica e social. Por isso, a hora do lanche deve ser proporcionada com prazer e alegria, buscando partilhar e trocar informações entre colegas, aprender a preparar e cuidar do alimento com independência, bem como, aprender a ter boas maneiras durante as refeições. 
Desse modo, uma rotina que contemple o entrelaçamento das ações fundamentais que configuram a Educação Infantil necessita de uma consciência crítica do educador em compreender que a rotina é responsável pela organização e cumprimento das metas preestabelecidas no dia-a-dia escolar visando, principalmente, o desenvolvimento integral da criança.

Por isso, a organização das atividades permanentes exige uma observação e compreensão do professor das necessidades e gostos da criança, para que o dia-a-dia na instituição seja envolvente e proveitoso

Logo, percebe-se a importância da rotina da educação infantil, que tem como objetivo organizar e situar tanto o aluno quanto o professor na elaboração e realização das atividades com seus alunos. Assim, por meio da rotina, da organização do tempo e do espaço, o educador pode atuar com confiança e autonomia, uma vez que a desorganização estressa não só adultos, mas as crianças também, então uma rotina estabelecida, flexiva, dinâmica e possível de ser adaptada com as situações do dia a dia, é assim como um planejamento adequado, é uma ferramenta indispensável para o cotidiano da educação infantil.

\section{CONSIDERAÇÕES FINAIS}

A rotina é fundamental para a organização das atividades diárias nas diversas instituições de ensino. No caso da Educação Infantil, além do aspecto organizacional das creches e pré-escolas, ela promove a segurança e autonomia das crianças. O professor que atua nesse nível de ensino pode organizar a rotina de sua turma a partir de diversos momentos, tais como: hora da roda, hora das atividades, hora do lanche, hora da higiene, hora da brincadeira e hora das atividades extraclasse. Acreditamos que a rotina escolar não pode ser tratada de uma forma mecânica, pelo contrário, toda atividade desenvolvida e os horários e espaços determinados para a realização das ações devem ser planejadas visando favorecer o trabalho pedagógico e as necessidades das crianças. Portanto, esperamos que o presente artigo promova um repensar sobre o trabalho que é desenvolvido na Educação Infantil e possa contribuir para uma reflexão sobre as rotinas estabelecidas nessas instituições. 


\section{REFERÊNCIAS}

BARBOSA, Maria C. S. A Rotina nas Pedagogias da Educação Infantil: dos binarismos à complexidade, Currículo sem Fronteiras, v.6, n.I, p. 56-69, Jan/Junzoo6. Disponível em:http://www.curriculosemfronteiras.org/vol6issıarticles.

Acesso em 03/o7/2012.

BRASIL. Ministério da Educação e do Desporto. Secretaria da Educação Fundamental. Referenciais Curriculares Nacionais para a Educação Infantil. Brasília: MEC/SEF, vol.ı, z e 3, 1998.

MANTAGUTE, ELISÂNGELA L.L. Rotinas na Educação Infantil. Disponível em: http://200.195.151.86/sites/educacao/images/stories/elisangelarotinas_na_educacao_infantil.pdf. Acesso em 03/o7/2012.

MASSENA, Renata S. Entrelaçamentos Entre as Concepções do Educar e do Cuidar na Educação Infantil. Disponível em: http://www.uneb.br/salvador/dedc/files/20II/o5/MonografiaRenata-da-Silva-Massena.pdf. Acesso em 03/o7/2012.

THIESSEN, Maria Lucia; BEAL, Ana Rosa. Pré-Escola, Tempo de Educar. São Paulo: Ática, 1998.

RAUL, Maria Cristina TroisDornels. A ludicidadena educação: uma atitude pedagógica /Maria Cristina Trois Dorneles Rau. -Curitiba: Ibpex, 2007.

LA TAILLE, Yves de I951- Piaget, Vygotsky, Wallon: teorias psicogenéticas em discussão/Yves de La Taille, Marta Kohl de Oliveira, Heloysa Dantas. - São Paulo: Summus, 1992. 